\title{
Defining the lateral limits of the endoscopic endonasal transtuberculum transplanum approach: anatomical study with pertinent quantitative analysis
}

\author{
*Alberto Di Somma, MD, ${ }^{1}$ Jorge Torales, MD, ${ }^{2}$ Luigi Maria Cavallo, MD, PhD, ${ }^{1}$ Jose Pineda, MS, ${ }^{3}$ \\ Domenico Solari, MD, PhD, ${ }^{1}$ Rosa Maria Gerardi, MD, ${ }^{1}$ Federico Frio, MD, ${ }^{1}$ \\ Joaquim Enseñat, MD, PhD, ${ }^{2}$ Alberto Prats-Galino, MD, PhD, ${ }^{3}$ and Paolo Cappabianca, MD ${ }^{1}$
}

1Division of Neurosurgery, Department of Neurosciences, Reproductive and Odontostomatological Sciences, Università degli Studi di Napoli Federico II, Naples, Italy; ${ }^{2}$ Department of Neurosurgery, Hospital Clinic, Barcelona, Spain; and ${ }^{3}$ Laboratory of Surgical NeuroAnatomy (LSNA), Faculty of Medicine, Universitat de Barcelona, Spain

\begin{abstract}
OBJECTIVE The extended endoscopic endonasal transtuberculum transplanum approach is currently used for the surgical treatment of selected midline anterior skull base lesions. Nevertheless, the possibility of accessing the lateral aspects of the planum sphenoidale could represent a limitation for such an approach. To the authors' knowledge, a clear definition of the eventual anatomical boundaries has not been delineated. Hence, the present study aimed to detail and quantify the maximum amount of bone removal over the planum sphenoidale required via the endonasal pathway to achieve the most lateral extension of such a corridor and to evaluate the relative surgical freedom.
\end{abstract}

METHODS Six human cadaveric heads were dissected at the Laboratory of Surgical NeuroAnatomy of the University of Barcelona. The laboratory rehearsals were run as follows: 1) preliminary predissection CT scans, 2) the endoscopic endonasal transtuberculum transplanum approach (lateral limit: medial optocarotid recess) followed by postdissection CT scans, 3) maximum lateral extension of the transtuberculum transplanum approach followed by postdissection CT scans, and 4) bone removal and surgical freedom analysis (a nonpaired Student t-test). A conventional subfrontal bilateral approach was used to evaluate, from above, the bone removal from the planum sphenoidale and the lateral limit of the endonasal route.

RESULTS The endoscopic endonasal transtuberculum transplanum approach was extended at its maximum lateral aspect in the lateral portion of the anterior skull base, removing the bone above the optic prominence, that is, the medial portion of the lesser sphenoid wing, including the anterior clinoid process. As expected, a greater bone removal volume was obtained compared with the approach when bone removal is limited to the medial optocarotid recess (average $533.45 \mathrm{vs} 296.07 \mathrm{~mm}^{2} ; \mathrm{p}<0.01$ ). The anteroposterior diameter was an average of $8.1 \mathrm{vs} 15.78 \mathrm{~mm}$, and the laterolateral diameter was an average of $18.77 \mathrm{vs} 44.54 \mathrm{~mm}(p<0.01)$. The neurovascular contents of this area were exposed up to the insular segment of the middle cerebral artery. The surgical freedom analysis revealed a possible increased lateral maneuverability of instruments inserted in the contralateral nostril compared with a midline target (average $384.11 \mathrm{vs}$ $\left.235.31 \mathrm{~mm}^{2} ; \mathrm{p}<0.05\right)$.

CONCLUSIONS Bone removal from the medial aspect of the lesser sphenoid wing, including the anterior clinoid process, may increase the exposure and surgical freedom of the extended endoscopic endonasal transtuberculum transplanum approach over the lateral segment of the anterior skull base. Although this study represents a preliminary anatomical investigation, it could be useful to refine the indications and limitations of the endoscopic endonasal corridor for the surgical management of skull base lesions involving the lateral portion of the planum sphenoidale.

https://thejns.org/doi/abs/10.3171/2017.9.JNS171406

KEYWORDS extended endoscopic endonasal; transtuberculum transplanum; skull base surgery; anterior cranial base; pituitary surgery

* A.D.S. and J.T. contributed equally to this work. 
$\mathrm{T}$ HE extended endoscopic endonasal transtuberculum transplanum approach has been claimed, over the past decades, to be a versatile route for accessing the suprasellar area..$^{2-4,10,11,21,24,39,45,48-50}$ Despite initial doubts related to the possibility of safely accessing neurovascular structures and pathologies via the nose, this technique has been widely accepted for the treatment of select midline anterior skull base lesions, such as craniopharyngiomas and/or meningiomas, after it was determined that this approach is effective and safe. 12,13,17,20,22,23,30,31,35-37,40,42,46,53

Nevertheless, one of the major limitations of the endoscopic endonasal approach concerns the possibility of accessing the lateral aspects of the planum sphenoidale. Indeed, to the authors' knowledge, a clear definition of the eventual anatomical boundaries has not been delineated.

In fact, from a strictly anatomical point of view, the medial optocarotid recess has been identified as the most lateral limit of bone opening at the level of the tuberculum sellae when performing an extended endonasal approach to the suprasellar area. ${ }^{8,15}$ On the other hand, from a surgical standpoint, it must be remembered that anterior skull base meningiomas could feature a wide dural attachment at the level of the planum, thus increasing the risk of incomplete tumor resection via the endoscopic endonasal route..$^{38}$

Building on recent anatomical contributions describing the possibility of approaching the optic nerve via the endoscopic endonasal corridor, as well as initial clinical series reporting the removal of tumors extending beyond the midline, ${ }^{18,19,29,31,33}$ this anatomical study aimed to detail and quantify the maximum amount of bone removal over the planum sphenoidale required to achieve the most lateral extension of the endonasal route.

We collected anatomical quantitative data pertaining to visualization of the suprasellar space to rule out advantages and limitations of this laterally expanded corridor compared with the conventional transplanum transtuberculum approach. Moreover, an analysis of surgical freedom (that is, an estimate of the range of possible movements of a surgeon's instruments in the region of interest) was calculated at the level of the maximum lateral extension over the planum sphenoidale and compared with that granted by the conventional transtuberculum transplanum route.

With this study, we intend to better define the lateral limits of anatomical exposure and surgical maneuverability of the endoscopic endonasal approach over the planum sphenoidale, providing a quantitative analysis of bone removal and a dynamic evaluation of the possible surgical freedom achieved via an endoscopic endonasal surgical window. To the authors' knowledge, this is the first study to report on such a topic and to discuss eventual clinical applications, including quantitative analysis.

\section{Methods \\ Anatomical Dissections}

Anatomical dissections were performed at the Laboratory of Surgical NeuroAnatomy of the Human Anatomy and Embryology Unit, University of Barcelona, Spain. Endoscopic endonasal approaches were performed using a rigid endoscope $4 \mathrm{~mm}$ in diameter and $18 \mathrm{~cm}$ in length, with $0^{\circ}$ and $30^{\circ}$ optic lenses (Karl Storz). The endoscope was connected to a light source through a fiber-optic cable and to a high-definition camera (Endovision Telecam SL; Karl Storz). A bilateral endoscopic endonasal approach to the suprasellar area was performed in 6 cadaveric heads, in which the arterial system was injected with red latex. The microsurgical dissections for the subfrontal approach were run at magnifications ranging from $\times 3$ to $\times 40$ (OPMI; Zeiss). This study was approved by the institutional review board of the University of Barcelona.

All specimens underwent multislice helical CT scanning (Siemens SOMATOM Sensation 64), with 0.6-mmthick axial spiral sections and a $0^{\circ}$ gantry angle before and after each dissection; 5 screws were implanted in the skull specimen as permanent bone reference markers to allow coregistration with the neuronavigation system (Medtronic, Inc., Surgical Technologies). Imaging data were transferred to the laboratory navigation-planning workstation, and point registration was performed. A registration correlation tolerance of $2 \mathrm{~mm}$ was considered acceptable.

Hence, cadaveric dissections were performed as follows.

\section{Endoscopic Endonasal Approach to the Planum Sphenoidale (midline approach)}

This approach was achieved according to the general principles detailed in previous publications. ${ }^{1,8,15,27}$ Access to the suprasellar structures was provided by drilling out the tuberculum sellae, namely, the suprasellar notch, ${ }^{15}$ up to the level of both medial optocarotid recesses, laterally, and in the anterior direction up to the level of the posterior ethmoidal arteries. In the interest of lowering bias, we used an image guidance system to repeat bone removal at these predefined limits and also to compare quantitative values retrieved from the conventional approach with those measured at the maximum lateral extension.

\section{Maximum Lateral Extension of the Endonasal Approach Over the Planum Sphenoidale}

The bone opening over the planum sphenoidale was extended further laterally by means of the following steps.

A wider corridor was obtained inside the nasal cavities by removing the middle ethmoid cells along with medial antrostomy to expose and access the inferior and medial orbital walls ${ }^{19}$ the lamina papyracea was then removed. Wide anterior sphenoidectomy and removal of the posterior portion of the nasal septum were obtained as well. Moving posteriorly, the posterior ethmoidal artery in its osseous channel was isolated to identify the anterior limit of the approach. The bony optic canal was opened in a proximal-to-distal direction, up to the lateral edge of the tuberculum sellae. Hence, after removal of the medial orbital wall, together with the medial part of the optic canal, it was possible to expose the bone forming the medial portion of the lesser sphenoid wing, up to the anterior clinoid process. The anterior clinoid process is a bony projection from the lesser sphenoid wing; it is directed posteriorly (that is, deeply) from an endonasal perspective.

Anteriorly, the anterior clinoid process is directed to the medial end of the lesser sphenoid wing. Medially, there are 2 attachments: the anterior and posterior roots. The anterior root forms the roof of the optic canal. The pos- 
terior root of the anterior clinoid process, also called the optic strut, forms the floor of the optic canal and separates it from the superior orbital fissure. From the endonasal perspective, this region is exposed through the supraoptic area or recess (in a well-pneumatized sphenoid sinus), the removal of which is one of the key steps to achieving further lateral extension over the planum sphenoidale. The supraoptic area or recess has a pyramidal shape with a base that abuts the sphenoid sinus and an apex that corresponds to the anterior clinoid process and the body of the lesser sphenoid wing: drilling of this area starts from the base of the pyramid and proceeds deeply in a medial-tolateral direction toward the anterior clinoid process. This pyramidal bone area is limited inferiorly by the intracanalicular portion of the optic nerve, which represents the main anatomical landmark to be preserved.

\section{Subfrontal Approach}

A conventional subfrontal approach was used to observe the bone removal over the planum sphenoidale achieved via the endonasal route. The surgical procedure started with a bicoronal skin incision, and thereafter a bifrontal craniotomy was completed. The dura mater was opened in a $U$ shape along the anterior orbital bone edge and reflected posteriorly. The falx cerebri was cut and the frontal lobes were retracted, thereby allowing transcranial visualization of the bone removal over the anterior cranial base via the endoscopic endonasal route.

\section{Quantitative Analysis, Statistical Analysis, 3D Reconstruction, and Surgical Freedom}

To calculate the bone opening obtained with the midline transtuberculum transplanum approach, the following anatomical landmarks were taken into account: p1, right medial optocarotid recess; $\mathrm{p} 2$, left medial optocarotid recess; $\mathrm{p} 3$, a point anterior to $\mathrm{p} 1$ located at the level of the posterior ethmoidal artery; and $\mathrm{p} 4$, a point anterior to $\mathrm{p} 2$ located at the level of the posterior ethmoidal artery.

For the maximum lateral extension, the bone removal was calculated taking into account the following points: $\mathrm{p} 1$, the most lateral and posterior point at the level of the planum sphenoidale (right side); p2, the most lateral and anterior point at the level of the planum sphenoidale (right side, at the level of the posterior ethmoidal artery); p3, the most lateral and posterior point at the level of the planum sphenoidale (left side); and p4, the most lateral and anterior point at the level of the planum sphenoidale (left side, at the level of the posterior ethmoidal artery).

Cartesian coordinates of each point were then obtained from the neuronavigation working station, which yielded 3 vectors, used to delineate 2 juxtaposed triangles. Bone removal was calculated as the sum of the area of these 2 triangles.

A virtual 3D model showing the bone removal was created using Amira, which is imaging software for the visualization and manipulation of biomedical data (Visage Imaging, Inc.). The reconstructions used for the illustrative case, however, were performed with the Brainlab navigation system (Brainlab Curve). Bony structures were segmented from DICOM images using a semiautomatic threshold-based process, and then a smoothing feature was applied to further improve the rendering of bony surfaces. Furthermore, using OsiriX (OsiriX Foundation) and Amira software, we analyzed postdissection CT scans to calculate the transverse (laterolateral) and anteroposterior dimensions along the flat portion of the skull base.

Following complete bone removal, the surgical freedom of operating instruments was calculated in each nostril, as previously described ${ }^{14,18}$ For the midline approach, a point at the level of the tuberculum sellae was used as a reference point; on the other hand, a point corresponding to the most anterior and lateral portion of the anterior clinoid of each side was used as a reference point for the maximum lateral extension approach. Surgical freedom was then calculated as described elsewhere.

All data were uploaded into Microsoft Excel, and a nonpaired Student t-test was used to calculate statistical differences.

\section{Results}

\section{Qualitative Assessment of Surgical Approaches}

Endoscopic Endonasal Transtuberculum Transplanum Midline Approach

The main anatomical structures that can be observed during this approach have been described in the pertinent literature. Briefly, after the dura mater is opened, the chiasmatic cistern and the lamina terminalis cistern are exposed. In the chiasmatic cistern, the anterior margin of the chiasm and the medial portion of the optic nerves are clearly visible. After the arachnoid of the lamina terminalis cistern is opened, the $A_{1}$ segments of both of the anterior cerebral arteries, the anterior communicating artery, the recurrent artery of Heubner, and the $\mathrm{A}_{2}$ segments and gyri recti of the frontal lobes are visible. The lamina terminalis is observed over the optic chiasm and posterior to the anterior cerebral artery-anterior communicating artery complex; its opening leads to the third ventricle cavity (Fig. 1). In this case, the supraoptic recess was not removed.

\section{Endoscopic Endonasal Transtuberculum Transplanum Approach: Maximum Lateral Extension}

Removal of the inferior and medial orbital walls, achieved via the endonasal route, permitted access to the most lateral portion of the planum sphenoidale (Supplemental Fig. S1). Using a $30^{\circ}$ endoscope, the dura mater overlying the lesser sphenoid wings and the periorbita was reached (Supplemental Fig. S2). Angled endoscopes were useful during the maximum lateral extension over the planum sphenoidale via the endonasal route. They permitted visualization of the most lateral aspect of the planum sphenoidale; furthermore, they were useful in performing the subsequent intradural exploration. From a technical standpoint, using a $30^{\circ}$ lens pointing laterally, it was easier to work with 2 instruments, thus avoiding the crowding of endoscopic instruments that can occur while moving laterally in the supraoptic recess area. Hence, this region was limited inferiorly by the intracanalicular portion of the optic nerve and the most superior aspect of the orbit and superiorly by the dura mater of the lateral portion of the anterior skull base. 

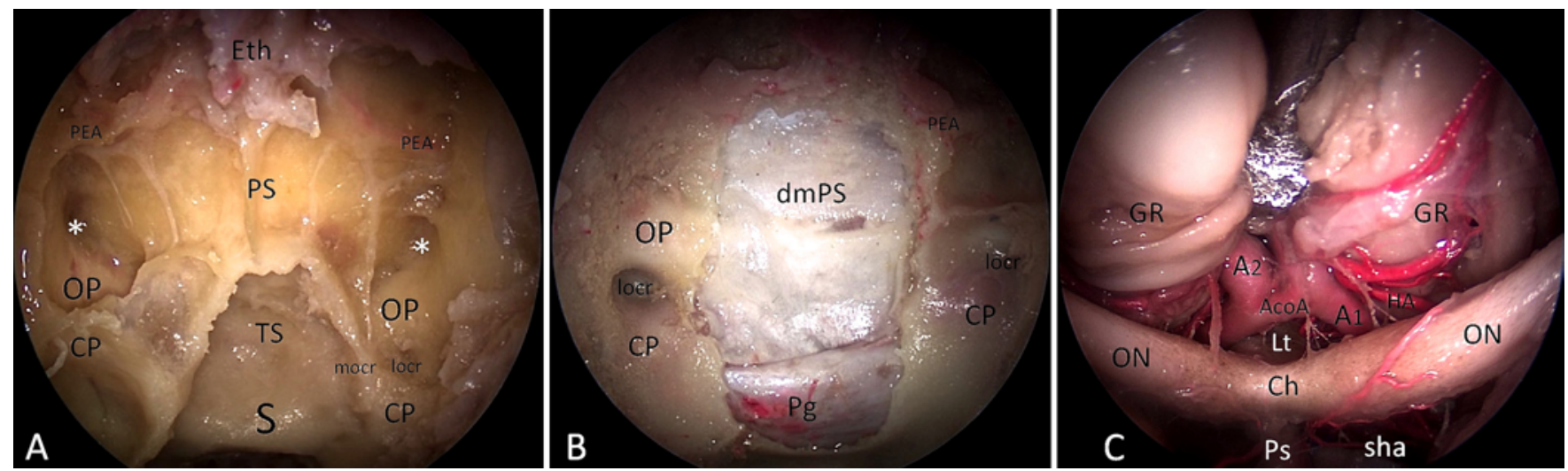

FIG. 1. A: Endoscopic endonasal view of the sella, tuberculum sellae, and planum sphenoidale. B: The transtuberculum transplanum approach has been performed. C: Intradural close-up view of the suprasellar area provided by the transtuberculum transplanum approach. $A c o A=$ anterior communicating artery; $A_{1}=$ precommunicating segment of the anterior cerebral artery; $A_{2}$ $=$ postcommunicating segment of the anterior cerebral artery; $\mathrm{Ch}=$ optic chiasm; $\mathrm{CP}=$ carotid protuberance; $\mathrm{dmPS}=$ dura mater of the planum sphenoidale; Eth = cribriform plate; $\mathrm{GR}=$ gyrus rectus; $\mathrm{HA}=$ Heubner artery; locr = lateral optocarotid recess; $\mathrm{Lt}=$ lamina terminalis; mocr = medial optocarotid recess; $\mathrm{ON}=$ optic nerve; $\mathrm{OP}=$ optic protuberance; $\mathrm{PEA}=$ posterior ethmoidal artery; $\mathrm{Pg}=$ pituitary gland; $\mathrm{PS}=$ pituitary stalk; $\mathrm{PS}$ = planum sphenoidale; $\mathrm{S}$ = sella; sha = superior hypophyseal artery; $\mathrm{TS}=$ tuberculum sellae; ${ }^{*}=$ supraoptic recess. Figure is available in color online only.

Drilling of this area started from the base of the pyramid, namely, the supraoptic recess, and proceeded deeply toward the anterior clinoid process in a medial-to-lateral direction. This permitted removal of the most medial portion of the lesser sphenoid wing overlying the orbit, thus releasing the first of 3 supporting structures for the anterior clinoid process, as well as extending laterally the bone removal over the planum sphenoidale. Subsequently, the optic canal roof, representing the second supporting structure of the anterior clinoid process, is removed in a medial-to-lateral direction using a 3-mm diamond burr. During in vivo procedures, continuous irrigation is mandatory to prevent thermal damage to surrounding neural structures (Fig. 2).

Thereafter, the bone of the anterior clinoid process was removed (Fig. 3). The anterior clinoid process is now connected only at the floor of the optic canal by the optic strut, which corresponds to the lateral optocarotid recess from the endonasal perspective. The optic strut can be removed as needed (Fig. 4). However, removal of the optic strut does not influence the maximum lateral extension over the planum sphenoidale via the endoscopic endonasal approach, and it may be troublesome; thus, it should be considered only in appropriate clinical cases.

After the dura was opened laterally, the sylvian cistern came into view; hence, an intradural exploration of the main neurovascular structures was due. The middle cerebral artery bifurcation was observed without mobilizing the optic nerve, and it was possible to follow it laterally at the level of its insular portion and medially reaching the internal carotid artery bifurcation (Fig. 4). Laterally and below the frontal lobe, both the anterior perforating substance receiving perforators from the middle cerebral artery (that is, from the lenticulostriate arteries from the prebifurcation part of the sphenoidal segment of the middle cerebral artery $\left.\left[\mathrm{M}_{1}\right]\right)$ and the recurrent artery of Heubner could be recognized.

Sliding deeper, the $M_{1}$ was exposed between the fron- tal and temporal lobes, that is, within the sylvian cistern up to its bifurcation (Fig. 5). From its origin, the middle cerebral artery courses laterally below the anterior perforated substance and posteriorly in a trajectory parallel to the sphenoid ridge. In addition, the temporopolar artery (an early cortical branch of the $\mathrm{M}_{1}$ supplying the temporopolar region) could be identified just anteriorly to the lenticulostriate arteries. Bifurcation of the middle cerebral artery could be explored up to the genu, limiting the beginning of the insular segment of the middle cerebral artery $\left(\mathbf{M}_{2}\right)$ (Supplemental Fig. S3). An artistic illustration (Supplemental Fig. S4) shows the panoramic, comprehensive view that can be obtained with such an endoscopic endonasal route (Fig. 6, Video 1).

VIDEO 1. Clip showing maximum lateral extension of the endonasal approach over the planum sphenoidale. The surgical lateral extension has been performed on the right side. After middle turbinectomy and lateralization of the contralateral middle turbinate, removal of the ethmoid cells is performed on the right side. A wide anterior sphenoidotomy with removal of the posterior portion of the nasal septum is performed. A medial antrostomy, with removal of the bulla ethmoidalis and the uncinated process, is performed on the right nasal cavity. The inferior and medial orbital walls are exposed; the lamina papyracea is identified and then removed. Moving posteriorly, the posterior ethmoidal artery in its osseous channel is isolated. After adequate lateral space has been obtained in the lateral portion of the nasal cavity, drilling can start at the midline: the sella, tuberculum sellae, and planum sphenoidale are removed. The supraoptic recess is identified because its removal is one of the key steps to achieving further lateral extension over the planum sphenoidale. Hence, drilling proceeds along the bone forming the medial portion of the lesser sphenoid wing. Subsequently, the optic canal roof, which represents the second of 3 supporting structures for the anterior clinoid process, is drilled out. Afterward, the floor of the optic canal, which is the lateral optocarotid recess from the endonasal perspective and is the third of its 3 supporting structures, is gently removed and the main neurovascular structures in this region are identified. The intradural exploration starts at the midline and continues laterally, taking advantage of removal of the supraoptic recess area: the optic chiasm with the lamina terminalis, 

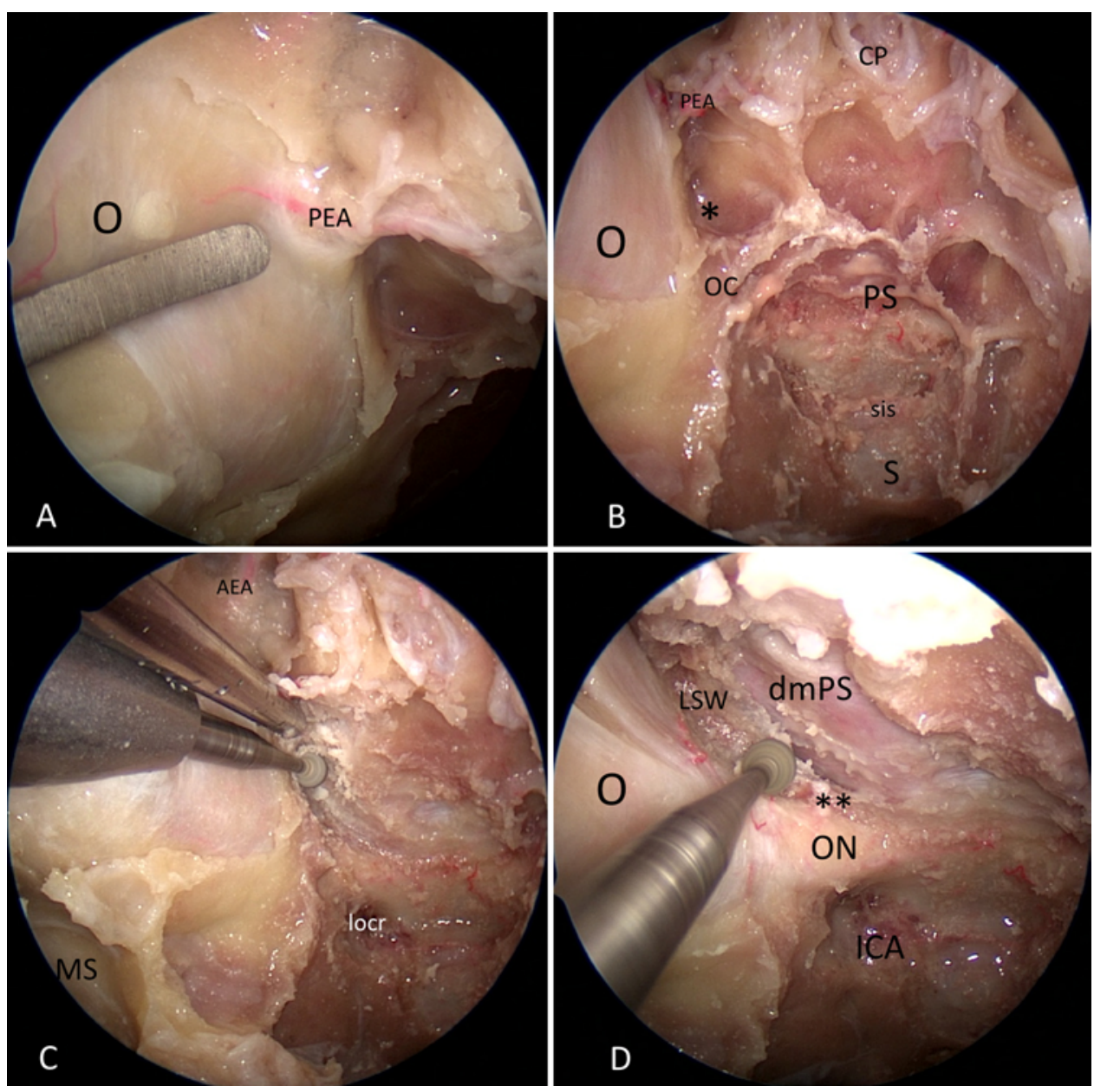

FIG. 2. A: First step to obtain right lateral extension over the planum sphenoidale via the endoscopic endonasal route. After the lamina papyracea is removed, the posterior ethmoidal artery is isolated. B: The supraoptic recess/area is reached. C: The most medial portion of the lesser sphenoid wing, continuing medially (that is, intracranially from the endonasal perspective) with the anterior clinoid process and placed superiorly to the periorbital area, is exposed and progressively drilled out. D: Afterward, the optic canal roof is removed. $\mathrm{AEA}=$ anterior ethmoidal artery; $\mathrm{CP}=$ cribriform plate; $\mathrm{dmPS}=$ dura mater of the planum sphenoidale; ICA = internal carotid artery; locr = lateral optocarotid recess; $L S W=$ lesser sphenoid wing; $M S=$ maxillary sinus; $O=$ orbit; $O C=$ optic canal; $\mathrm{ON}=$ optic nerve; $\mathrm{PEA}=$ posterior ethmoidal artery; $\mathrm{PS}=$ planum sphenoidale; $\mathrm{S}$ = sella; sis = superior intercavernous sinus; ${ }^{*}=$ supraoptic recess; ${ }^{*}=$ optic canal roof. Figure is available in color online only.

the anterior communicating artery-cerebral artery complex, and the pituitary stalk below the optic chiasm can be appreciated at the midline. Above the supraoptic recess, the $\mathrm{M}_{1}$ is exposed between the frontal and temporal lobes; more laterally, the middle cerebral artery bifurcation is observed. At the end, below the frontal lobe, both the anterior perforating substance receiving perforators from the middle cerebral artery (that is, from the lenticulostriate arteries from the prebifurcation part of the $M_{1}$ ) and the recurrent artery of Heubner are recognized. Copyright Laboratory of Surgical NeuroAnatomy, Faculty of Medicine, University of Barcelona. Published with permission. Click here to view.

\section{Subfrontal Approach}

The subfrontal route allowed an overview of the anterior cranial base craniectomy that was performed by means of the endoscopic endonasal corridor. Such a surgical window was evaluated before and after the dural opening, to detail with the transcranial view the maximum lateral extension over the planum sphenoidale gained by the endo- scopic endonasal transtuberculum transplanum approach (Supplemental Fig. S5).

\section{Quantitative Analysis of Bone Removal}

As expected, quantitative analysis showed that the amount of bone removal required to achieve the most lateral aspect of the planum sphenoidale was higher than that for the conventional endoscopic endonasal transtuberculum transplanum approach (Fig. 7). In particular, with the midline route, the average amount of bone removal was $296.07 \mathrm{~mm}^{2}$ (range 201.42-381.73 $\mathrm{mm}^{2}$; SD $61.71 \mathrm{~mm}^{2}$ ), with an average anteroposterior diameter of $8.1 \mathrm{~mm}$ (range 5.56-9.65 mm; SD $1.7 \mathrm{~mm}$ ) and an average laterolateral diameter of $18.77 \mathrm{~mm}$ (range 17.04-21.40 mm; SD $1.47 \mathrm{~mm}$ ). On the other hand, with maximum lateral extension of the approach, the obtained area of bone removal was 533.45 $\mathrm{mm}^{2}$ (range 326.03-695.31 $\mathrm{mm}^{2}$; SD $170.70 \mathrm{~mm}^{2}$ ), with an average anteroposterior diameter of $15.78 \mathrm{~mm}$ (range 

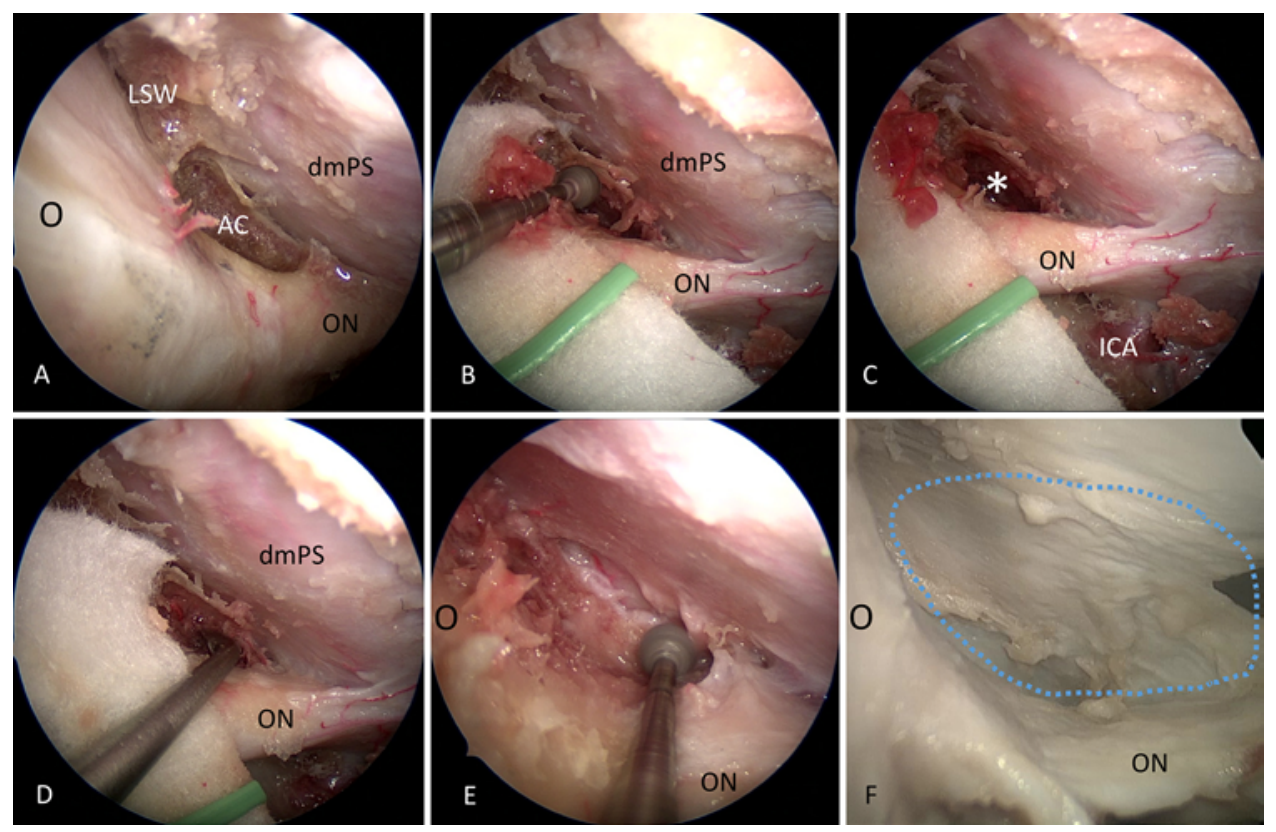

FIG. 3. Endoscopic endonasal exposure of the base of the anterior clinoid process (A) after removing the most medial portion of the lesser wing overlying the orbit and the optic canal roof (see Fig. 2). The anterior clinoid process is progressively drilled out (B) up to the exposure of its central cancellous bone (C), which can be removed with a spoon (D) and/or a diamond drill (E). Accordingly, exposure of the dura covering the supraoptic area can be obtained $(F)$. AC = anterior clinoid; dmPS = dura mater of the planum sphenoidale; ICA = internal carotid artery; LSW = lesser sphenoid wing; $\mathrm{O}=$ orbit; $\mathrm{ON}=$ optic nerve; ${ }^{*}=$ cancellous bone of the anterior clinoid; dotted line $=$ dura mater behind the supraoptic recess. Figure is available in color online only.
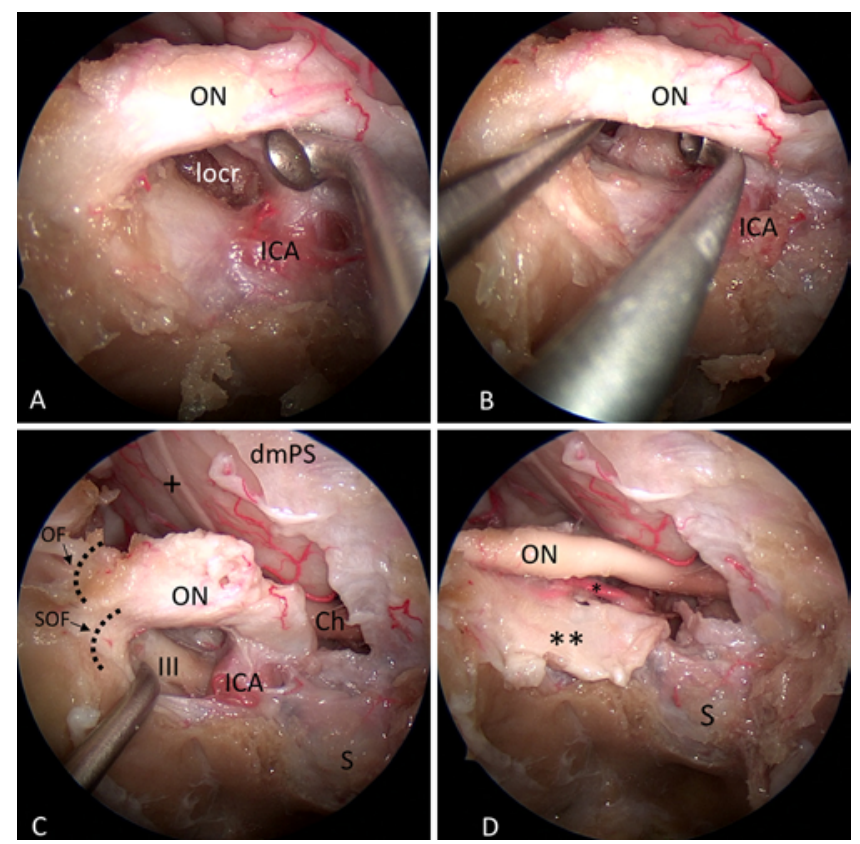

FIG. 4. Endoscopic endonasal removal of the bone forming the lateral optocarotid recess, namely, the optic strut, which is the last of the 3 supporting structures of the anterior clinoid process (A and B). The pertinent neurovascular anatomy is also shown (C) after opening of the optic nerve sheath (D). $\mathrm{Ch}=$ optic chiasm; dmPS = dura mater planum sphenoidale; $I C A=$ internal carotid artery; locr = lateral optocarotid recess; $\mathrm{OF}=$ optic foramen; $\mathrm{ON}=$ optic nerve; $\mathrm{S}=$ sella; $\mathrm{SOF}=$ superior orbital fissure; III = third cranial nerve; + = olfactory nerve; ${ }^{*}=$ ophthalmic artery; ${ }^{* *}=$ optic nerve sheath. Figure is available in color online only.
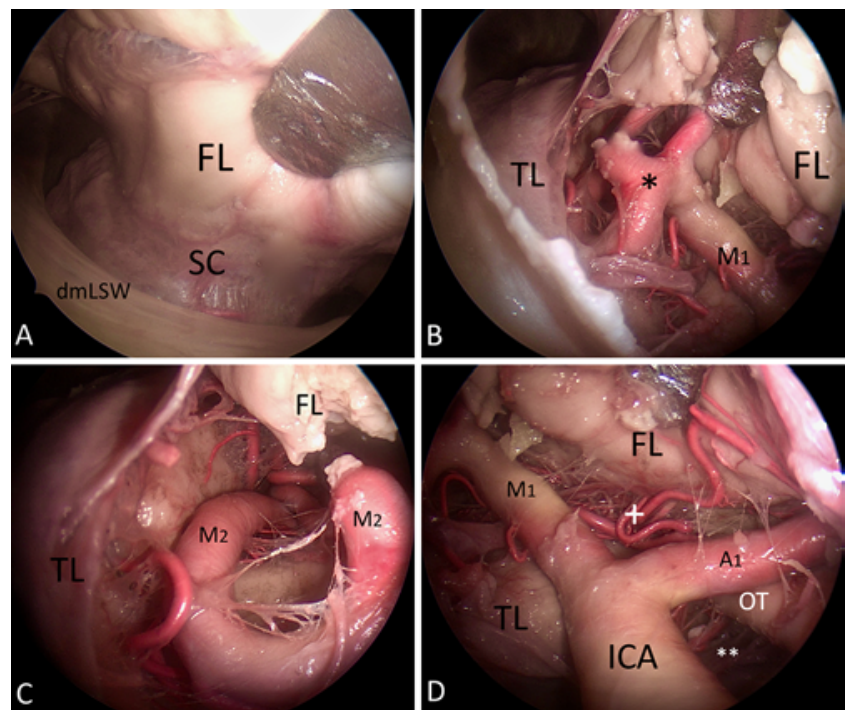

FIG. 5. After opening of the dura mater of the right supraorbital recess (as shown in Fig. 3F), the intradural structures are visualized. Opening of the sylvian cistern (A). The middle cerebral artery bifurcation is observed (B) and followed laterally at the level of the insula (C) and medially up to the level of the internal carotid artery bifurcation (D). A = precommunicating segment of the anterior cerebral artery; $\mathrm{dmLSW}=$ dura mater of the lesser sphenoid wing; $F L=$ frontal lobe; $I C A=$ internal carotid artery; $\mathrm{M}_{1}$ = sphenoidal segment of the middle cerebral artery; $\mathrm{M}_{2}=$ insular segment of the middle cerebral artery; OT = optic tract; $\mathrm{SC}=$ sylvian cistern; $\mathrm{TL}=$ temporal lobe; + = perforators (including the Heubner artery) directed to the right anterior perforated substance; ${ }^{*}=$ middle cerebral artery bifurcation; ${ }^{* *}=$ perforators directed to the posterior perforated substance. Figure is available in color online only. 

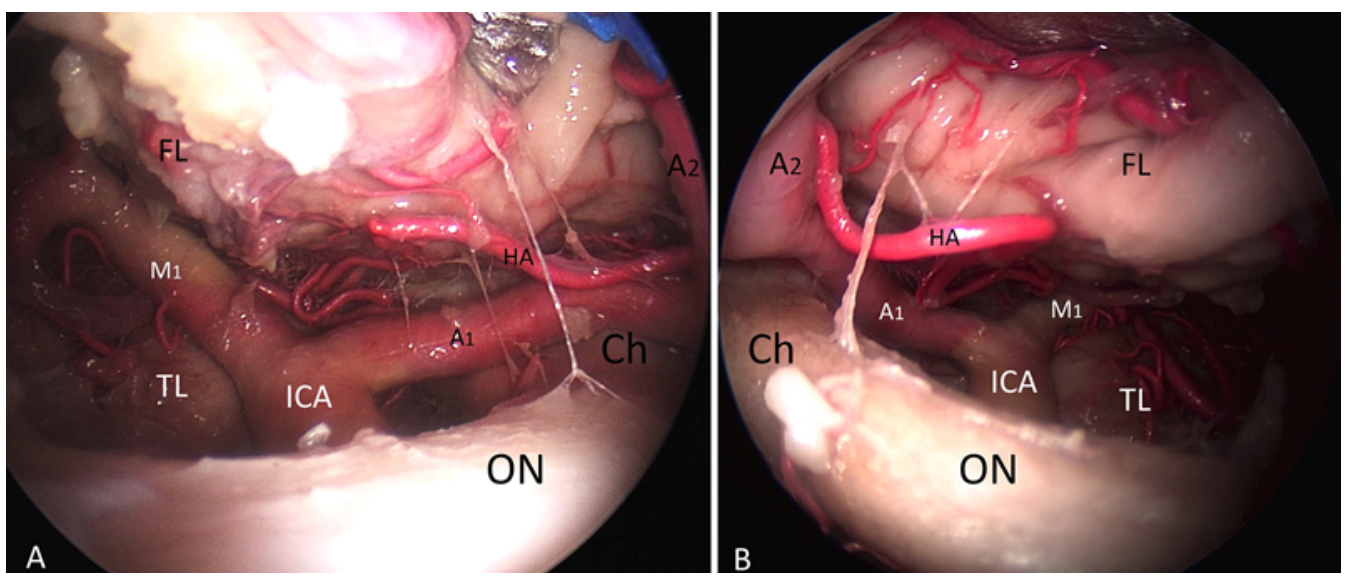

FIG. 6. Intradural exploration through both supraorbital recesses after opening of the sylvian cisterns (A, right side; $\mathbf{B}$, left side). $A_{1}=$ precommunicating segment of the anterior cerebral artery; $A_{2}=$ postcommunicating segment of the anterior cerebral artery; $\mathrm{Ch}=$ optic chiasm; $\mathrm{FL}=$ frontal lobe; $\mathrm{HA}=$ Heubner artery; $\mathrm{ICA}=$ internal carotid artery; $\mathrm{M}_{1}=$ sphenoidal segment of the middle cerebral artery; $\mathrm{ON}=$ optic nerve; $\mathrm{TL}=$ temporal lobe. Figure is available in color online only.

13.34-18.06 mm; SD $1.87 \mathrm{~mm}$ ) and an average laterolateral diameter of $44.54 \mathrm{~mm}$ (range 35.46-52.22 mm; SD $6.30 \mathrm{~mm}$ ). As expected, these differences were statistically significant ( $<<0.01$; Supplemental Fig. S6, Tables 1 and 2).

\section{Surgical Freedom Analysis}

Surgical freedom was calculated at the level of the tuberculum sellae for the conventional transtuberculum transplanum approach in both the right and left nostrils (Fig. 8). On the other hand, surgical freedom at the maximum lateral extension was measured separately for each side in the homolateral and then the contralateral nostril; thereafter, the 2 areas were merged. Surgical freedom at
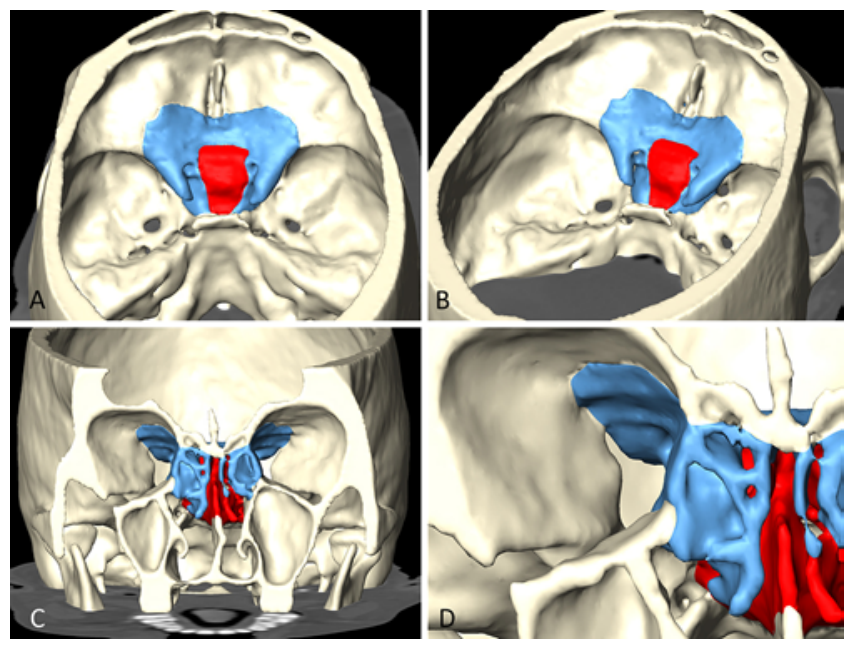

FIG. 7. 3D reconstructions of the postdissection CT scans in axial (A), oblique (B), and coronal (C) perspectives demonstrating the midline transtuberculum transplanum route (red) and the approach at its maximum lateral extension (blue). Details of the supraorbital recess removed via the endonasal route have been provided (D). The 3D reconstructions were obtained in a sample specimen using Amira. The same colors were used in the bar graphs summarizing our results (Fig. 9). Figure is available in color online only. the most anterior and lateral portion of the anterior clinoid in the contralateral nostril had the greatest area $(384.11 \pm$ $173.85 \mathrm{~mm}^{2}$ ), after proper extension of the approach (as detailed in the Anatomical Dissections section). According to surgical freedom data, maneuverability of the transtuberculum transplanum approach was increased at lateral maximum extension in the contralateral nostril compared with the conventional corridor ( $p<0.05$; Fig. 9, Table 3).

\section{Illustrative Case}

A 40-year-old man suffered a mild traumatic brain injury and underwent basal CT scanning, which showed an incidental large mass attached to the planum sphenoidale. Due to previous implants that were not compatible with MRI, he underwent contrast-enhanced CT scanning that confirmed the presence of the mass, which extended to the

TABLE 1. Quantitative data concerning the bone removal over the planum sphenoidale obtained with the endonasal endoscopic standard and maximum extension approaches

\begin{tabular}{|c|c|c|c|}
\hline \multirow[b]{2}{*}{$\begin{array}{l}\text { Specimen } \\
\text { No. }\end{array}$} & \multicolumn{2}{|c|}{$\begin{array}{c}\text { Bone Removal Over the Planum } \\
\text { Sphenoidale }\left(\mathrm{mm}^{2}\right)\end{array}$} & \multirow[b]{2}{*}{ Statistical Data } \\
\hline & $\begin{array}{c}\text { Midline } \\
\text { Transtuberculum } \\
\text { Transplanum } \\
\text { Approach }\end{array}$ & $\begin{array}{l}\text { Max Lat } \\
\text { Extension of the } \\
\text { Transtuberculum } \\
\text { Transplanum } \\
\text { Approach }\end{array}$ & \\
\hline 1 & 268.263 & 471.629 & \\
\hline 2 & 332.269 & 357.114 & \\
\hline 3 & 381.727 & 700.776 & \\
\hline 4 & 201.42 & 649.868 & \\
\hline 5 & 278.186 & 695.31 & \\
\hline 6 & 314.581 & 326.034 & \\
\hline Mean & 296.0743333 & 533.4551667 & \multirow{2}{*}{$\begin{array}{c}p<0.01 ; t=3.2035 \\
d f=10\end{array}$} \\
\hline SD & 61.7119688 & 170.6970524 & \\
\hline
\end{tabular}

$\mathrm{df}=$ degrees of freedom; $\mathrm{t}=$ Student's $\mathrm{t}$-test value. 
TABLE 2. Quantitative data concerning the dimensions of bone removal over the planum sphenoidale obtained with the endonasal endoscopic midline transtuberculum transplanum and maximum extension approaches

\begin{tabular}{|c|c|c|c|c|c|c|}
\hline \multirow{3}{*}{$\begin{array}{l}\text { Specimen } \\
\text { No. }\end{array}$} & \multicolumn{4}{|c|}{ Dimensions of Bone Removal Over the Planum Sphenoidale (mm) } & & \\
\hline & \multicolumn{2}{|c|}{$\begin{array}{l}\text { Midline Transtuberculum } \\
\text { Transplanum Approach }\end{array}$} & \multicolumn{2}{|c|}{$\begin{array}{l}\text { Max Lat Extension of the } \\
\text { Transtuberculum Transplanum Approach }\end{array}$} & \multicolumn{2}{|c|}{ Statistical Data } \\
\hline & AP Length & LL Length & AP Length & LL Length & AP Length & LL Length \\
\hline 1 & 6.46 & 17.04 & 17.58 & 52.22 & & \\
\hline 2 & 5.56 & 18.9 & 18.06 & 50.35 & & \\
\hline 3 & 9.65 & 19 & 14.59 & 35.46 & & \\
\hline 4 & 8.43 & 21.4 & 13.34 & 45.56 & & \\
\hline 5 & 8.96 & 17.93 & 14.65 & 43.78 & & \\
\hline 6 & 9.54 & 18.33 & 16.45 & 39.87 & & \\
\hline Average & 8.1 & 18.77 & 15.78 & 44.54 & $p<0.01 ; t=7.4346$ & $p<0.01 ; t=9.7532$ \\
\hline SD & 1.70 & 1.47 & 1.87 & 6.30 & $\mathrm{df}=10$ & $\mathrm{df}=10$ \\
\hline
\end{tabular}

$\mathrm{AP}=$ anteroposterior $; \mathrm{LL}=$ laterolateral.

left anterior skull base and partially involved the left optic canal. The results of neurological examination were otherwise normal. Our diagnostic hypothesis was a planum sphenoidale meningioma (Fig. 10).

After careful consideration of many factors, including the patient's age and considerable size of the lesion with possible natural growth behavior, we decided to treat the tumor using an extended endoscopic endonasal transtuberculum transplanum approach.

Accordingly, the endonasal route to the planum sphe- noidale was used, and it was extended laterally to the left to properly manage the cleavage plane between the tumor and normal brain tissue. After total tumor resection, the tumor cavity could be observed from the endonasal perspective (Fig. 11). An effective watertight closure was mandatory to prevent postoperative CSF leakage. In this case, as well as in many of the other extended approaches we perform for such types of lesions, we used a multilayer technique. First, the surgical cavity was filled with fat graft. Afterward, 2 layers of dural substitute were used.
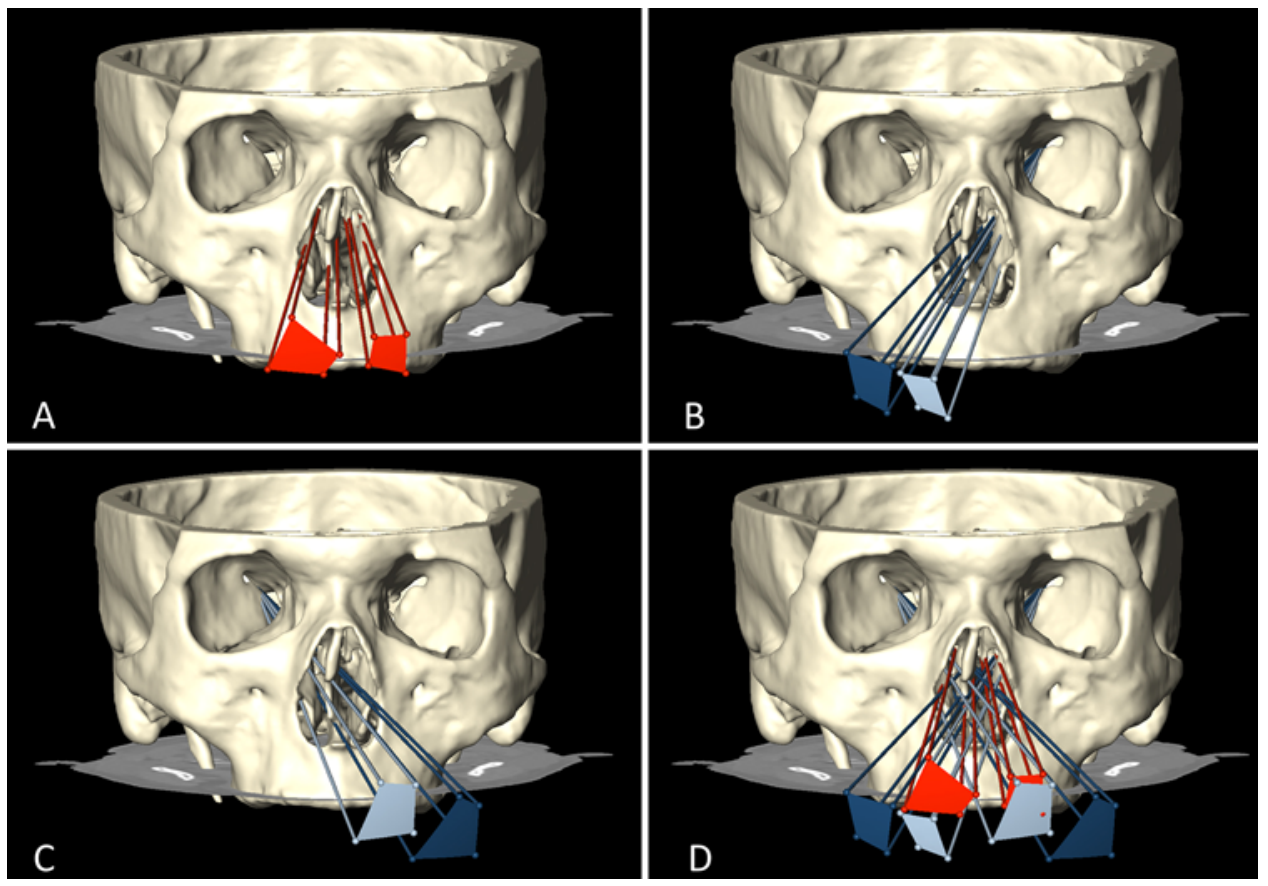

FIG. 8. 3D reconstructions in a ventral perspective of the surgical freedom areas calculated for the midline and maximum lateral extension approaches. A: Midline surgical freedom is represented by red. B: Lateral extension to the left is represented by different colors according to the entry nostril and using the same colors as the bar graphs summarizing our results, namely, light blue if the instruments crossed the homolateral nostril and dark blue if they came from the contralateral nostril (see Fig. 9). C: Lateral extension to the right. D: Comprehensive reconstruction including all results of our surgical freedom analysis from both nostrils. The 3D reconstructions were obtained in a sample specimen using Amira. Figure is available in color online only. 

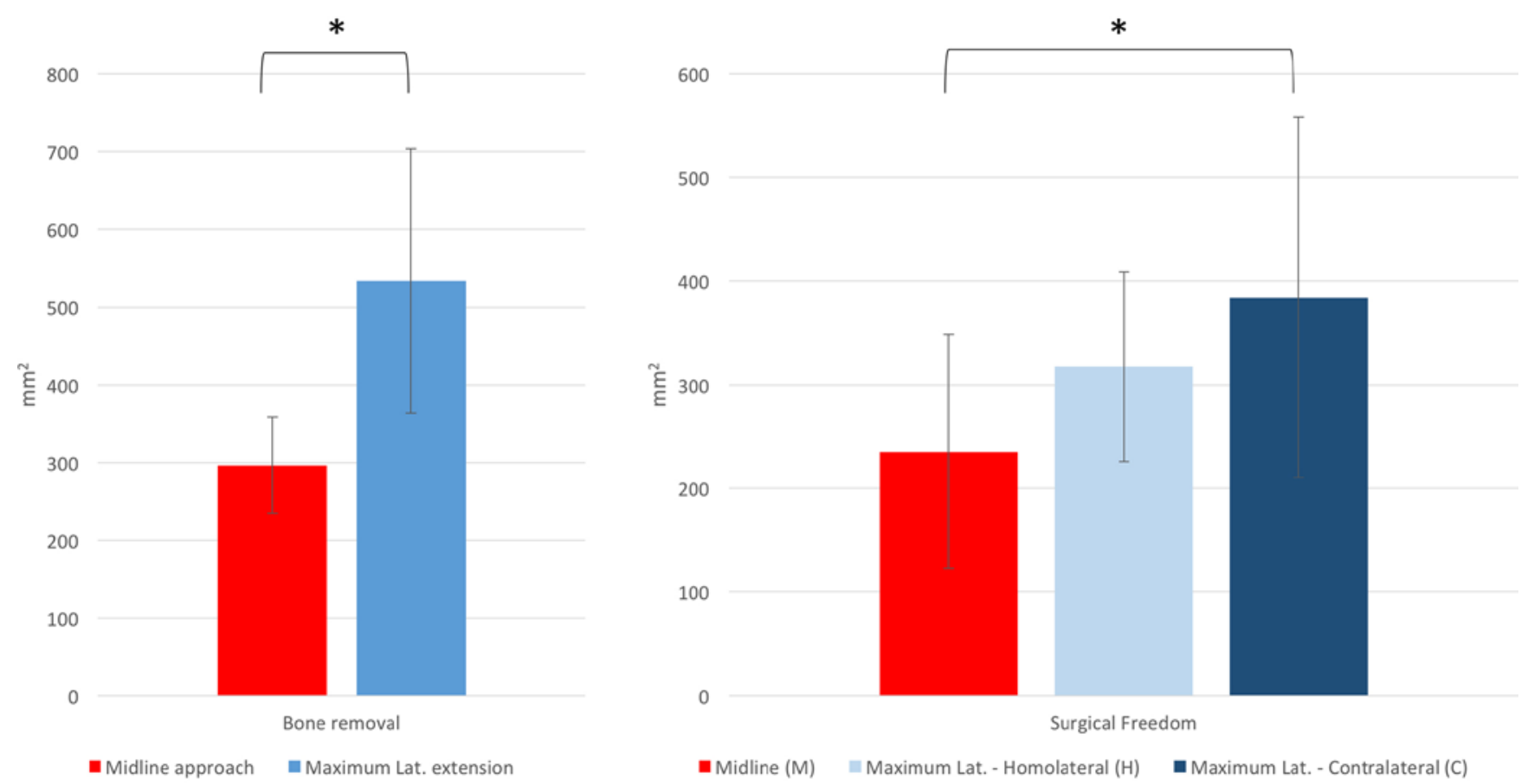

FIG. 9. Quantitative analysis of bone removal (left) and surgical freedom (right). For the bone removal analysis, the midline approach is represented by red and the maximum lateral extension approach is depicted in blue. As expected, compared with the midline endoscopic endonasal transtuberculum transplanum approach, its maximum lateral extension featured a larger bone removal ( ${ }^{*} p<0.01$, left). For the surgical freedom analysis, the surgical freedom to a midline target is represented by red and the surgical freedom to a lateral target is depicted in light blue if the instruments crossed the homolateral nostril and in dark blue if they came from the contralateral nostril. The surgical freedom at the most anterior and lateral portion of the anterior clinoid in the contralateral nostril resulted in the greatest area and reached statistical significance compared with the surgical freedom at the midline ( ${ }^{*} p<0.05$, right). Figure is available in color online only.

TABLE 3. Surgical freedom analysis concerning the midline transtuberculum transplanum approach and the maximum lateral extension from the homolateral and contralateral nostrils

\begin{tabular}{|c|c|c|c|c|c|c|}
\hline \multirow[b]{2}{*}{$\begin{array}{l}\text { Specimen } \\
\text { No.* }^{*}\end{array}$} & \multicolumn{3}{|c|}{ Surgical Freedom Analysis $\left(\mathrm{mm}^{2}\right)$} & \multicolumn{3}{|c|}{ Statistical Data } \\
\hline & $\begin{array}{l}\text { Midline From Lt } \\
\text { \& Rt Nostril (M) }\end{array}$ & $\begin{array}{c}\text { Max Lat From } \\
\text { Homolat Nostril }(\mathrm{H})\end{array}$ & $\begin{array}{c}\text { Max Lat From } \\
\text { Contralat Nostril (C) }\end{array}$ & $\mathrm{M}$ vs $\mathrm{H}$ & $M$ vs $C$ & $\mathrm{H}$ vs $\mathrm{C}$ \\
\hline 1 & 205.687 & 286.666 & 186.334 & & & \\
\hline 1 & 178.384 & 243.691 & 181.613 & & & \\
\hline 2 & 235.567 & 318.867 & 350.987 & & & \\
\hline 2 & 245.879 & 317.985 & 386.856 & & & \\
\hline 3 & 220.697 & 301.873 & 390.877 & & & \\
\hline 3 & 236.796 & 320.987 & 386.283 & & & \\
\hline 4 & 399.345 & 481.231 & 554.833 & & & \\
\hline 4 & 265.407 & 357.422 & 450.375 & & & \\
\hline 5 & 253.098 & 273.527 & 650.558 & & & \\
\hline 5 & 455.434 & 453.403 & 641.796 & & & \\
\hline 6 & 67.408 & 326.871 & 107.977 & & & \\
\hline 6 & 60.05 & 125.978 & 320.854 & & & \\
\hline Mean & 235.3126667 & 317.3750833 & 384.1119167 & & & \\
\hline SD & 112.7898518 & 91.56722901 & 173.8495505 & & & \\
\hline Surgical freedom & & & & $\begin{array}{l}p=0.0632 ; t=1.9567 ; \\
\quad d f=22\end{array}$ & $\begin{array}{l}p<0.05 ; t=2.4873 \\
\quad d f=22\end{array}$ & $\begin{array}{l}p=0.2519 ; t=1.1766 ; \\
\quad d f=22\end{array}$ \\
\hline
\end{tabular}

$\mathrm{C}=$ surgical freedom calculated from the contralateral nostril at a point corresponding to the most anterior and lateral portion of the anterior clinoid process; $\mathrm{H}=$ surgical freedom calculated from the homolateral nostril at a point corresponding to the most anterior and lateral portion of the anterior clinoid process; $\mathrm{M}=$ surgical freedom calculated at the level of the tuberculum sellae.

* Specimen number repeated as values were calculated for each side. 

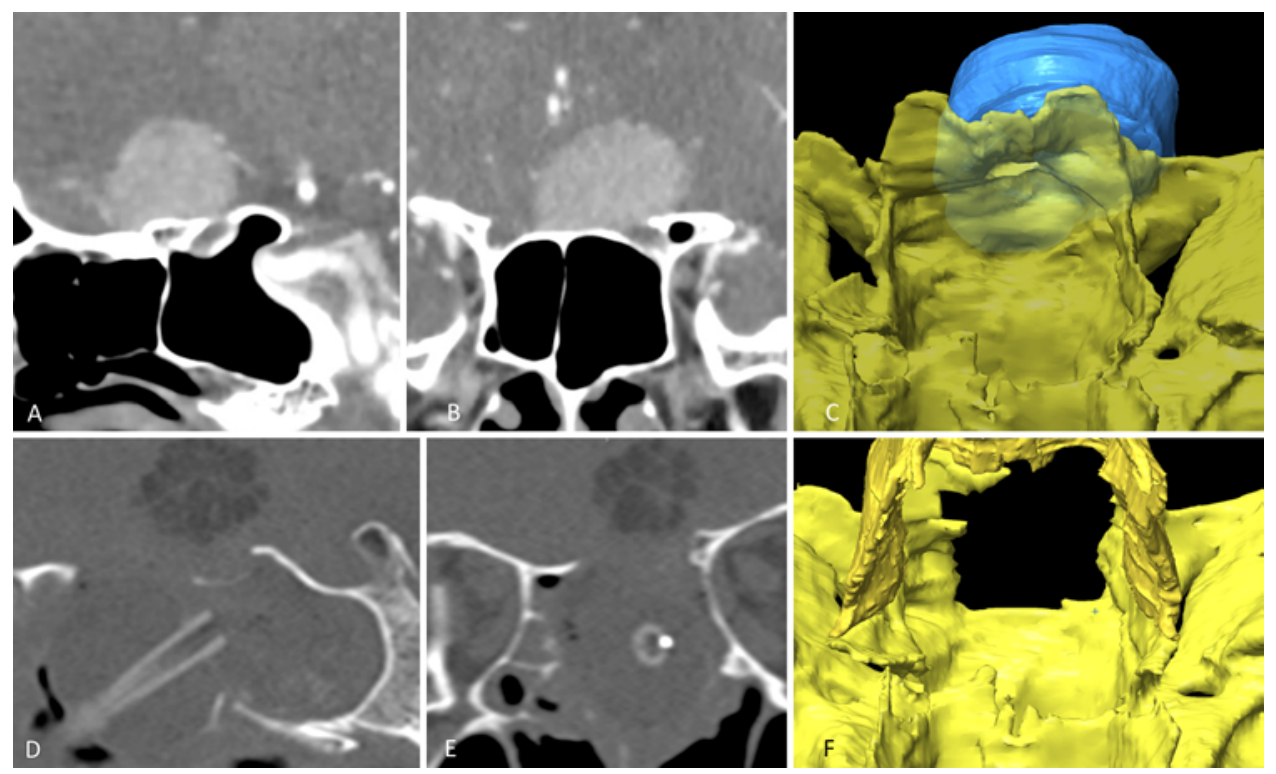

FIG. 10. Preoperative sagittal (A) and coronal (B) postcontrast CT scans with 3D volume-rendered reconstruction, as seen from an endonasal perspective (C) of planum sphenoidale meningioma extending to the left anterior skull base and with partial involvement of the left optic canal. Postoperative sagittal (D) and coronal (E) postcontrast CT scans with 3D volume-rendered reconstruction $(F)$ show that total tumor removal was achieved with the endonasal approach. 3D reconstructions were made using the Brainlab Curve navigation system. Figure is available in color online only.

The first layer was positioned intradurally and the second between the dura and the bone. To support the materials used for reconstruction at the level of the skull base defect, a nasoseptal flap was used with fibrin glue and Surgicel. An inflated Foley balloon catheter, filled with 7-8 $\mathrm{ml}$ of saline solution, was then placed in the sphenoid sinus to support the reconstruction.

The patient's postoperative hospital course was uneventful; he was discharged to home on postoperative day 6. A histopathological examination confirmed our diagnostic hypothesis.

\section{Discussion}

Usually, anterior cranial base lesions are approached via different transcranial approaches that have been adopted safely and effectively by the vast majority of neurosurgeons. In recent years, the evolution of transcranial surgery and the refinement of minimally invasive techniques, such as endoscope-assisted transcranial resection, have resulted in better outcomes with increased removal ratios, improved visual outcomes, and lower morbidity and mortality rates. ${ }^{44,51}$

At the same time, the endoscopic endonasal approach has significantly evolved since its initial introduction in pituitary and sinonasal surgery, $, 5,6,26,28,52$ and several anatomical and surgical series have reported its efficacy and advantages for the treatment of selected skull base lesions. In fact, the development and advancement of expanded endoscopic transnasal surgery has provided a good surgical option that has several advantages in well-selected cases compared with transcranial routes.

Different tumors involving the suprasellar area (for example, meningiomas ${ }^{31-33}$ and craniopharyngiomas ${ }^{9,10,49}$ ) can be treated by means of the endoscopic endonasal cor- ridor, with pros and cons that have been clearly highlighted in the pertinent literature. ${ }^{16,34,43,47}$ Adopting the endoscopic endonasal route has many benefits, including the possibility of accessing the skull base via a direct shorter corridor, the reduction of brain and neurovascular retraction, improved visualization, and a favorable angle of attack for dealing with some tumors.

However, the postoperative rates of CSF leaks cannot yet be considered negligible. In particular, for anterior cranial base meningiomas (including tuberculum sellae, clinoid, and sphenoorbital meningiomas), which are often responsible for vision loss related to intracranial and/ or intracanalicular optic nerve involvement, the endonasal technique may have a concrete risk of incomplete tumor resection. In fact, it has recently been proven that wider dural attachments, together with cavernous internal carotid artery involvement, can be considered predictors of incomplete tumor resection via the endonasal route. ${ }^{38}$

However, building on our knowledge and experience in endoscopic endonasal surgery, we have been able to expand the indications for this technique to include skull base diseases of the midline, mainly to achieve bony decompression of the optic nerves. ${ }^{7,19,25,31,41}$ Because of that, this anatomical study aimed to detail and quantify the maximum amount of bone removal over the planum sphenoidale to achieve the most lateral extension of the endonasal corridor and to rule out the relative surgical freedom analysis.

Our results showed that further lateral removal of the planum sphenoidale (in particular at the level of the supraoptic sphenoidal recess, which corresponds intracranially to the lesser sphenoid wing) permits management of the most lateral aspects of the anterior cranial base. Accordingly, the intradural contents were exposed up to the anterior aspect of the insular segment of the middle cerebral 

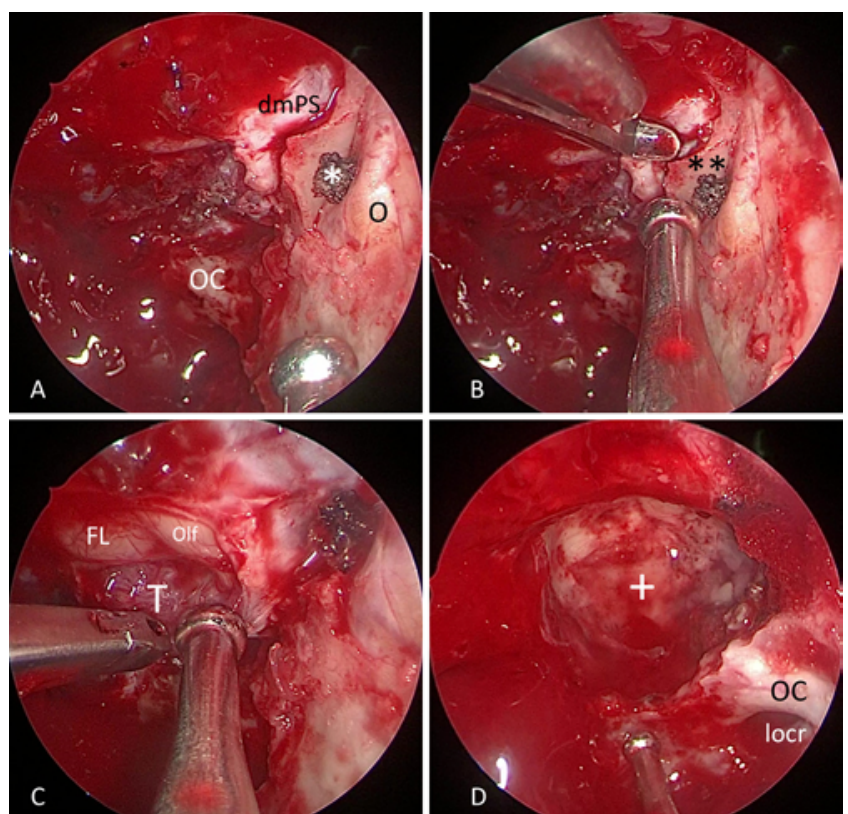

FIG. 11. Endoscopic endonasal approach for the planum sphenoidale meningioma shown in Fig. 10. The lamina papyracea was removed, exposing the medial aspect of the periorbita; the posterior ethmoidal artery was coagulated (A). The lesser sphenoid wing was partially removed (B) to clearly identify the cleavage plane between tumor and surrounding brain tissue (C). The tumor cavity is shown after complete tumor removal (D). dmPS = dura mater of the planum sphenoidale; FL $=$ frontal lobe; locr = lateral optocarotid recess; $\mathrm{O}=$ orbit; $\mathrm{OC}=$ optic canal; Olf = olfactory nerve; $\mathrm{T}$ = tumor; + = tumor cavity; ${ }^{*}=$ coagulated posterior ethmoidal artery; ${ }^{* *}=$ lesser sphenoid wing. Figure is available in color online only.

artery. Obviously, compared with the standard endoscopic endonasal transtuberculum transplanum approach, its maximum lateral extension featured a larger bone removal (average 533.45 vs $296.07 \mathrm{~mm}^{2} ; \mathrm{p}<0.01$ ) with larger anteroposterior and laterolateral diameters (average $8.1 \mathrm{vs}$ $15.78 \mathrm{~mm}$ and 18.77 vs $44.54 \mathrm{~mm}$, respectively; $\mathrm{p}<0.01$ ).

On the other hand, the surgical freedom analysis revealed that the degree of possible surgical movements at the most lateral aspect of the surgical field was greater than the degree obtained at the midline target, when instruments are slid inside of the contralateral nostril and after proper extension of the approach, as detailed previously; this difference was statistically significant (average 384.11 vs $235.31 \mathrm{~mm}^{2}$; $\mathrm{p}<0.05$ ).

In this regard, possible clinical scenarios in which maximum extension of the endoscopic endonasal transtuberculum transplanum approach should be adopted need to be clearly defined in the pertinent surgical setting. Indeed, when dealing with tuberculum sellae meningiomas with lateral extension along the lesser sphenoid wing, the optic canal, and the orbital roof, the lateral extension could be useful to properly manage the dural attachment and to peel the tumor off of the optic nerve and/or arachnoid layers. In addition, several craniopharyngiomas with some parasellar extension may require this expanded corridor over the planum sphenoidale. It must be stressed that, when dealing with pathologies that extend beyond the midline (that is, involving the lateral aspect of the planum sphenoidale), in- traoperative Doppler ultrasound would be of great help by permitting one to check the position of the internal carotid artery as well as the other major intracranial vessels that may be encountered.

Moreover, because this approach requires an extensive removal of the skull base via the endonasal route, the reconstruction technique needed to close the osteodural defect should be discussed. A variety of reconstruction methods and materials are available and used. At our institution, even in cases of lateral extension over the planum sphenoidale, we first perform an intradural closure with obliteration of the dead space, using small pieces of autologous fat and fibrin glue.

Then, we prefer to use the so-called sandwich technique, whereby the surgical cavity is filled with fat graft sutured to 3 layers of fascia lata or dural substitute. The first 2 layers are positioned intradurally and the third one extradurally, wedged between the dura and the bone. A pedicled nasoseptal flap is used to cover the skull base defect and the posterior wall of the sphenoid sinus. It must be stressed that, in the most lateral aspect of the skull base defect (where the optic nerve stands), it is difficult to perform an inlay-overlay of dural substitutes, which is also due to the irregularity of the osteodural opening. Accordingly, proper reconstruction in this region requires the placement of autologous fat pieces crossing the intraextradural space that will be subsequently covered by the nasoseptal flap.

The boundaries of these approaches are slowly changing as the anatomical perspective is defined, surgical experience is gained, techniques are refined, instrumentation is improved, and complications are addressed. Hence, this study may modify the indications for the endoscopic endonasal route to the anterior cranial skull base, especially for tumors that grow along the skull base in a coronal, rather than a sagittal, plane.

\section{Study Limitations}

As with any cadaveric study, the clinical applications of our findings are limited: tumor consistency, relative displacement of neurovascular structures, prior treatment, and specific anatomical interhuman variability of the internal carotid artery course could all affect to different degrees the outcome of the endoscopic endonasal approach.

In the interest of lowering interhuman variability biases, we set up bone opening limits both at the level of the medial optocarotid recesses (laterally) and at the level of the posterior ethmoidal arteries (anteriorly). Although bone opening may be tailored to specific case needs in a clinical scenario, such predefined limits helped us to perform a valid quantitative comparison between the conventional approach and the maximum lateral extension of the endonasal approach.

Moreover, it cannot be underestimated that the degree of sphenoid sinus pneumatization can influence the amount of bone removal over the anterior cranial base. However, notwithstanding a less pneumatized sphenoid sinus (that is, the conchal-type sinus), the planum sphenoidale and the optic canal may also be identified and opened. On the other hand, it is worth remembering that the extensive drilling required to decompress the optic canal could cause thermal damage to the optic nerve. 


\section{Conclusions}

The present study demonstrates the possibility of removing the medial portion of the lesser wing of the sphenoid bone and the anterior clinoid process through the endoscopic endonasal route. This additional bone removal may significantly increase the exposure and surgical freedom of the extended endoscopic endonasal transtuberculum transplanum approach over the lateral segment of the anterior skull base.

Quantitative analysis of the maximum lateral extension obtained showed significant improvement compared with conventional bone removal up to the medial optocarotid recess $(\mathrm{p}<0.01)$. The surgical freedom analysis showed good results of surgical movements, also in the most lateral aspect of this surgical window. Although this study represents a preliminary anatomical investigation, it could be useful to refine the indications and limitations of the endoscopic endonasal corridor for the surgical management of skull base lesions involving or extending to the lateral portion of the planum sphenoidale. Nevertheless, further anatomical and clinical studies are necessary to address not merely what can be done but also what should be done.

\section{Acknowledgments}

We thank Francesco Colaleo, MD, for the artistic illustration for this study. This work was partly supported by the grant "Marató TV3 Project" (411/U/2011 - TITLE: Quantitative analysis and computer-aided simulation of minimally invasive approaches for intracranial vascular lesions).

\section{References}

1. Abhinav K, Acosta Y, Wang WH, Bonilla LR, Koutourousiou M, Wang E, et al: Endoscopic endonasal approach to the optic canal: anatomic considerations and surgical relevance. Neurosurgery 11 (Suppl 3):431-446, 2015

2. Abou-Al-Shaar H, Blitz AM, Rodriguez FJ, Ishii M, Gallia GL: Expanded endonasal endoscopic approach for resection of an infrasellar craniopharyngioma. World Neurosurg 95:618.e7-618.e12, 2016

3. Ajayi O, Chakravarthy V, Hanna G, DeLos Reyes K: Surgical technique: endoscopic endonasal transphenoidal resection of a large suprasellar mixed germ cell tumor. Cureus 8:e503, 2016

4. Bander ED, Singh H, Ogilvie CB, Cusic RC, Pisapia DJ, Tsiouris AJ, et al: Endoscopic endonasal versus transcranial approach to tuberculum sellae and planum sphenoidale meningiomas in a similar cohort of patients. J Neurosurg 128:40-48, 2018

5. Cappabianca P, Cavallo LM, Esposito F, De Divitiis O, Messina A, De Divitiis E: Extended endoscopic endonasal approach to the midline skull base: the evolving role of transsphenoidal surgery. Adv Tech Stand Neurosurg 33:151-199, 2008

6. Castelnuovo P, Dallan I, Battaglia P, Bignami M: Endoscopic endonasal skull base surgery: past, present and future. Eur Arch Otorhinolaryngol 267:649-663, 2010

7. Castelnuovo P, Turri-Zanoni M, Battaglia P, Locatelli D, Dallan I: Endoscopic endonasal management of orbital pathologies. Neurosurg Clin N Am 26:463-472, 2015

8. Cavallo LM, de Divitiis O, Aydin S, Messina A, Esposito F, Iaconetta G, et al: Extended endoscopic endonasal transsphenoidal approach to the suprasellar area: anatomic considerations-part 1. Neurosurgery 62 (6 Suppl 3):1202-1212, 2008

9. Cavallo LM, Frank G, Cappabianca P, Solari D, Mazzatenta D, Villa A, et al: The endoscopic endonasal approach for the management of craniopharyngiomas: a series of 103 patients. J Neurosurg 121:100-113, 2014

10. Cavallo LM, Solari D, Esposito F, Villa A, Minniti G, Cappabianca $P$ : The role of the endoscopic endonasal route in the management of craniopharyngiomas. World Neurosurg 82 (6 Suppl):S32-S40, 2014

11. Ciric I, Farhat H, Raviv J: Transplanum approach to suprasellar lesions. World Neurosurg 82:e65-e66, 2014

12. de Divitiis E, Cavallo LM, Esposito F, Stella L, Messina A: Extended endoscopic transsphenoidal approach for tuberculum sellae meningiomas. Neurosurgery 62 (6 Suppl 3):1192-1201, 2008

13. de Divitiis E, Esposito F, Cappabianca P, Cavallo LM, de Divitiis O, Esposito I: Endoscopic transnasal resection of anterior cranial fossa meningiomas. Neurosurg Focus 25(6): E8, 2008

14. de Notaris M, Prats-Galino A: Surgical freedom: a challenging topic in endoscopic endonasal approaches. World Neurosurg 82:e387-e388, 2014

15. de Notaris M, Solari D, Cavallo LM, D'Enza AI, Enseñat J, Berenguer J, et al: The "suprasellar notch," or the tuberculum sellae as seen from below: definition, features, and clinical implications from an endoscopic endonasal perspective. J Neurosurg 116:622-629, 2012

16. Dehdashti AR, Stofko D, Okun J, Obourn C, Kennedy T: Endoscopic endonasal reconstruction of skull base: repair protocol. J Neurol Surg B Skull Base 77:271-278, 2016

17. Dhandapani S, Singh H, Negm HM, Cohen S, Souweidane MM, Greenfield JP, et al: Endonasal endoscopic reoperation for residual or recurrent craniopharyngiomas. J Neurosurg 126:418-430, 2017

18. Di Somma A, Andaluz N, Gogela SL, Cavallo LM, Keller JT, Prats-Galino A, et al: Surgical freedom evaluation during optic nerve decompression: laboratory investigation. World Neurosurg 101:227-235, 2017

19. Di Somma A, Cavallo LM, de Notaris M, Solari D, Topczewski TE, Bernal-Sprekelsen M, et al: Endoscopic endonasal medial-to-lateral and transorbital lateral-to-medial optic nerve decompression: an anatomical study with surgical implications. J Neurosurg 127:199-208, 2017

20. Ditzel Filho LF, Prevedello DM, Jamshidi AO, Dolci RL, Kerr EE, Campbell R, et al: Endoscopic endonasal approach for removal of tuberculum sellae meningiomas. Neurosurg Clin N Am 26:349-361, 2015 (Erratum in Neurosurg Clin N Am 26:xi, 2015)

21. Esquenazi Y, Essayed WI, Singh H, Mauer E, Ahmed M, Christos PJ, et al: Endoscopic endonasal versus microscopic transsphenoidal surgery for recurrent and/or residual pituitary adenomas. World Neurosurg 101:186-195, 2017

22. Fernandez-Miranda JC, Gardner PA, Snyderman CH: Endoscopic endonasal approach for tuberculum sellae meningiomas. Neurosurgery 69:E260-E261, 2011

23. Fernandez-Miranda JC, Pinheiro-Neto CD, Gardner PA, Snyderman $\mathrm{CH}$ : Endoscopic endonasal approach for a tuberculum sellae meningioma. Neurosurg Focus 32 (Suppl 1):E8, 2012

24. Fomichev D, Kalinin P, Kutin M, Sharipov O: Extended transsphenoidal endoscopic endonasal surgery of suprasellar craniopharyngiomas. World Neurosurg 94:181-187, 2016

25. Jacquesson T, Abouaf L, Berhouma M, Jouanneau E: How I do it: the endoscopic endonasal optic nerve and orbital apex decompression. Acta Neurochir (Wien) 156:1891-1896, 2014

26. Kassam A, Carrau RL, Snyderman CH, Gardner P, Mintz A: Evolution of reconstructive techniques following endoscopic expanded endonasal approaches. Neurosurg Focus 19(1):E8, 2005

27. Kassam A, Snyderman CH, Mintz A, Gardner P, Carrau RL: Expanded endonasal approach: the rostrocaudal axis. Part I. 
Crista galli to the sella turcica. Neurosurg Focus 19(1):E3, 2005

28. Kassam AB, Prevedello DM, Carrau RL, Snyderman CH, Thomas A, Gardner P, et al: Endoscopic endonasal skull base surgery: analysis of complications in the authors' initial 800 patients. J Neurosurg 114:1544-1568, 2011

29. Khan OH, Anand VK, Schwartz TH: Endoscopic endonasal resection of skull base meningiomas: the significance of a "cortical cuff" and brain edema compared with careful case selection and surgical experience in predicting morbidity and extent of resection. Neurosurg Focus 37(4):E7, 2014

30. Khan OH, Krischek B, Holliman D, Klironomos G, Kucharczyk W, Vescan A, et al: Pure endoscopic expanded endonasal approach for olfactory groove and tuberculum sellae meningiomas. J Clin Neurosci 21:927-933, 2014

31. Koutourousiou M, Fernandez-Miranda JC, Stefko ST, Wang EW, Snyderman CH, Gardner PA: Endoscopic endonasal surgery for suprasellar meningiomas: experience with 75 patients. J Neurosurg 120:1326-1339, 2014

32. Koutourousiou M, Fernandez-Miranda JC, Vaz-Guimaraes Filho F, de Almeida JR, Wang EW, Snyderman CH, et al: Outcomes of endonasal and lateral approaches to petroclival meningiomas. World Neurosurg 99:500-517, 2017

33. Koutourousiou M, Fernandez-Miranda JC, Wang EW, Snyderman $\mathrm{CH}$, Gardner PA: Endoscopic endonasal surgery for olfactory groove meningiomas: outcomes and limitations in 50 patients. Neurosurg Focus 37(4):E8, 2014

34. Kshettry VR, Do H, Elshazly K, Farrell CJ, Nyquist G, Rosen $\mathrm{M}$, et al: The learning curve in endoscopic endonasal resection of craniopharyngiomas. Neurosurg Focus 41(6):E9, 2016

35. Laufer I, Anand VK, Schwartz TH: Endoscopic, endonasal extended transsphenoidal, transplanum transtuberculum approach for resection of suprasellar lesions. J Neurosurg 106:400-406, 2007

36. Liu JK, Christiano LD, Patel SK, Tubbs RS, Eloy JA: Surgical nuances for removal of olfactory groove meningiomas using the endoscopic endonasal transcribriform approach. Neurosurg Focus 30(5):E3, 2011

37. Liu JK, Christiano LD, Patel SK, Tubbs RS, Eloy JA: Surgical nuances for removal of tuberculum sellae meningiomas with optic canal involvement using the endoscopic endonasal extended transsphenoidal transplanum transtuberculum approach. Neurosurg Focus 30(5):E2, 2011

38. Mascarella MA, Tewfik MA, Aldosari M, Sirhan D, Zeitouni A, Di Maio S: A simple scoring system to predict the resectability of skull base meningiomas via an endoscopic endonasal approach. World Neurosurg 91:582-591, 591.e1, 2016

39. Mattogno PP, Nasi D, Iaccarino C, Oretti G, Santoro L, Romano A: first case of primary sellar/suprasellar-intraventricular Ewing sarcoma: case report and review of the literature. World Neurosurg 98:869.e1-869.e5, 2017

40. Moussazadeh N, Prabhu V, Bander ED, Cusic RC, Tsiouris AJ, Anand VK, et al: Endoscopic endonasal versus open transcranial resection of craniopharyngiomas: a casematched single-institution analysis. Neurosurg Focus 41(6):E7, 2016

41. Netuka D, Masopust V, Belšán T, Profantová N, Beneš V: Endoscopic endonasal resection of medial orbital lesions with intraoperative MRI. Acta Neurochir (Wien) 155:455-461, 2013

42. Padhye V, Naidoo Y, Alexander H, Floreani S, Robinson S, Santoreneos S, et al: Endoscopic endonasal resection of anterior skull base meningiomas. Otolaryngol Head Neck Surg 147:575-582, 2012

43. Qureshi T, Chaus F, Fogg L, Dasgupta M, Straus D, Byrne RW: Learning curve for the transsphenoidal endoscopic endonasal approach to pituitary tumors. Br J Neurosurg 30:637-642, 2016
44. Ruggeri AG, Cappelletti M, Fazzolari B, Marotta N, Delfini $\mathrm{R}$ : Frontobasal midline meningiomas: is it right to shed doubt on the transcranial approaches? Updates and review of the literature. World Neurosurg 88:374-382, 2016

45. Sankhla SK, Jayashankar N, Khan GM: Endoscopic endonasal transplanum transtuberculum approach for retrochiasmatic craniopharyngiomas: operative nuances. Neurol India 63:405-413, 2015

46. Schwartz TH, Anand VK: The endoscopic endonasal transsphenoidal approach to the suprasellar cistern. Clin Neurosurg 54:226-235, 2007

47. Shou X, Shen M, Zhang Q, Zhang Y, He W, Ma Z, et al: Endoscopic endonasal pituitary adenomas surgery: the surgical experience of 178 consecutive patients and learning curve of two neurosurgeons. BMC Neurol 16:247, 2016

48. Solari D, Cavallo LM, Somma T, Chiaramonte C, Esposito F, Del Basso De Caro M, et al: Endoscopic endonasal approach in the management of Rathke's cleft cysts. PLoS One 10:e0139609, 2015

49. Solari D, Morace R, Cavallo LM, Amoroso F, Cennamo G, Del Basso DE Caro M, et al: The endoscopic endonasal approach for the management of craniopharyngiomas. J Neurosurg Sci 60:454-462, 2016

50. Temiz C, Kutlay M, Safali M, Kural C, Ezgu C, Izci Y: Endoscopic removal of suprasellar colloid cyst with interpeduncular and prepontine cisterns extension. World Neurosurg 98:869.e7-869.e12, 2017

51. Turel MK, Tsermoulas G, Yassin-Kassab A, Reddy D, Andrade-Barazarte H, Gonen L, et al: Tuberculum sellae meningiomas: a systematic review of transcranial approaches in the endoscopic era. J Neurosurg Sci [epub ahead of print], 2016

52. Wang AJ, Zaidi HA, Laws ED Jr: History of endonasal skull base surgery. J Neurosurg Sci 60:441-453, 2016

53. Wang Q, Lu XJ, Ji WY, Yan ZC, Xu J, Ding YS, et al: Visual outcome after extended endoscopic endonasal transsphenoidal surgery for tuberculum sellae meningiomas. World Neurosurg 73:694-700, 2010

\section{Disclosures}

The authors report no conflict of interest concerning the materials or methods used in this study or the findings specified in this paper.

\section{Author Contributions}

Conception and design: Cavallo. Acquisition of data: Torales, Pineda, Gerardi, Frio. Analysis and interpretation of data: Di Somma, Torales, Cavallo, Pineda. Drafting the article: Di Somma, Torales, Cavallo, Solari. Critically revising the article: Di Somma, Cavallo, Solari, Enseñat, Prats-Galino, Cappabianca. Reviewed submitted version of manuscript: all authors. Statistical analysis: Di Somma, Torales, Pineda, Prats-Galino. Study supervision: Cavallo, Prats-Galino, Cappabianca.

\section{Supplemental Information Videos}

Video 1. https://vimeo.com/243665435.

\section{Online-Only Content}

Supplemental material is available with the online version of the article.

Supplemental Figs. S1-S6. https://thejns.org/doi/suppl/10. 3171/2017.9.JNS171406.

\section{Correspondence}

Alberto Di Somma: Università degli Studi di Napoli Federico II, Naples, Italy. albertodisomma87@gmail.com. 